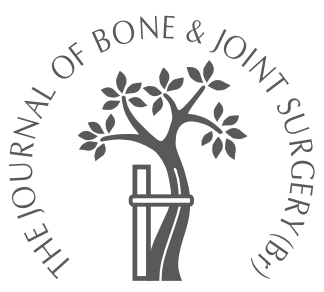

Y. Silbersack, B.-M. Taute, W. Hein, H. Podhaisky

From the Martin Luther University, Halle/Salle, Germany

Y. Silbersack, MD

W. Hein, MD, Professor

Department for

Orthopaedics and Physical

Medicine

B.-M. Taute, MD

H. Podhaisky, MD,

Professor

Department for Interna

Medicine III/Angiology

Magdeburger Strasse 22,

Martin Luther University

Halle-Wittenberg, 06097

Halle/Salle, Germany.

Correspondence should be sent to Dr Y. Silbersack.

C2004 British Editorial

Society of Bone and

Joint Surgery

doi:10.1302/0301-620X.86B6.

$13958 \$ 2.00$

$J$ Bone Joint Surg [Br]

2004;86-B:809-12.

Received 25 October 2002;

Accepted after revision

11 November 2003

\section{Prevention of deep-vein thrombosis after total hip and knee replacement}

\author{
LOW-MOLECULAR-WEIGHT HEPARIN IN COMBINATION WITH \\ INTERMITTENT PNEUMATIC COMPRESSION
}

After total hip (THR) or knee replacement (TKR), there is still an appreciable risk of developing deep-vein thrombosis despite prophylaxis with low-molecular-weight heparin (LMWH). In a prospective, randomised study we examined the efficacy of LMWH in combination with intermittent pneumatic compression in patients undergoing primary unilateral THR or TKR. We administered $40 \mathrm{mg}$ of enoxaparin daily to 131 patients combined with either the use of intermittent pneumatic compression or the wearing of graduated compression stockings.

Compression ultrasonography showed no evidence of thrombosis after LMWH and intermittent pneumatic compression. In the group with LMWH and compression stockings the prevalence of thrombosis was $28.6 \%$ (40\% after TKR, 14\% after THR). This difference was significant $(p<0.0001)$. In the early post-operative phase after THR and TKR, combined prophylaxis with LMWH and intermittent pneumatic compression is more effective than LMWH used with graduated compression stockings.

Thromboembolic complications are common after total hip (THR) and knee (TKR) replacement. ${ }^{1-3}$ Randomised studies have shown that even when using low-molecular-weight heparin (LMWH), there is still a phlebographically confirmed rate of thrombosis of up to $16 \%$ after THR and up to $31 \%$ after TKR. ${ }^{1,4}$ Since the development of venous thrombosis is multifactorial, prophylaxis should include a combination of pharmacological and physical treatments. ${ }^{4}$ Thus, the use of LMWH in combination with intermittent pneumatic compression (IPC) has been widely recommended for these patients, ${ }^{1,2,5}$ but the efficacy of this combination has not been established. Additional mechanical prophylaxis with graduated compression stockings (GCS) may have further benefit. ${ }^{1}$ The rate of thrombosis is $38 \%$ after THR and $68 \%$ after TKR when using GCS alone whereas it is $11 \%$ and $28 \%$, respectively, when using only IPC. ${ }^{1,4}$ The efficacy of IPC in patients at high risk may be comparable with that of pharmacological prophylaxis and in particular with LMWH.

Our aim in this prospective, randomised study was to investigate the rate of thrombosis in patients undergoing primary unilateral THR and TKR using combined prophylaxis with LMWH and IPC compared with LMWH and GCS. We also assessed the conditions for the optimal use of IPC for the maximum reduction of venous thrombosis. There are few indications in the literature as to the optimum duration of IPC; most cases only describe continuous use and the time of initiation before or after operation. ${ }^{6-13}$

\section{Patients and methods}

This prospective, randomised study was carried out between April 1999 and April 2000. The patients enrolled were at least 18 years of age and were awaiting primary unilateral THR or TKR.

Patients with a history of cardiac insufficiency (New York Heart Association) class III/ IV, stage III chronic renal insufficiency, severe peripheral arterial disease, acute thrombophlebitis, neurological disorders or arthrodeses of the lower limbs, recent anticoagulation, haemorrhagic diathesis, allergy to heparins and active malignant disease were excluded.

Before surgery, patients were randomly assigned to either the group receiving LMWH and IPC or to that receiving LMWH and GCS.

Between the sixth and the 12 th days and the sixth and the 12th weeks thromboembolic symptoms were recorded and compression ultrasonography of the deep-vein system was performed on both lower limbs. A SONOLINE Versa-Pro system (Siemens AG, München, Germany) with a 5 and $7.5 \mathrm{MHz}$ linear probe was used. The popliteal vein and more proxi- 
mal veins were examined with the patient supine and the distal veins with the patient in the sitting position with feet resting. Thrombosis was diagnosed if there were segments of non-compressible or only partially compressible vein. In order to confirm the findings, colour duplex ultrasonography was performed using the Acuson $128 \mathrm{XP} / 10$ system (Acuson $\mathrm{GmbH}$, Erlangen, Germany) by an independent angiologist who was unaware of the patients' participation in the study or of the method of prophylaxis. Spiral CT of the lungs was undertaken on those patients who were clinically suspected to have pulmonary embolism.

Nearly all the patients were mobilised fully weight-bearing on the first post-operative day.

The design of the study had the approval of the Ethical Committee and patients gave written informed consent.

Thromboembolic prophylaxis. A subcutaneous dose of 4000 IU of anti-Xa enoxaparin-natrium (Clexane $40 \mathrm{mg}$; Aventis Pharma, Bad Soden am Taunus, Germany) was given daily beginning on the evening prior to surgery. The simultaneous administration of LMWH with regional anaesthesia or the intra-operative introduction of an epidural or spinal catheter for post-operative analgesia was contraindicated because of the potentially increased risk of epidural or spinal haemorrhage. In such cases, heparin-natrium (Liquemin N 25.000; Hoffman-La Roche AG, GrenzachWyhlen, Germany) was initially administered, beginning with $5000 \mathrm{IU}$ on the evening before surgery, followed by a daily dose of $3 \times 5000$ IU until the changeover to LMWH.

Patients either wore class-I graduated compression stockings (Comprinet pro; Beyersdorf AG, Hamburg, Germany) applied to both legs directly after the operation or had IPC using the VenaFlow System with two-cell calf cuffs (Aircast Europa GmbH, Neubeuern, Germany). With this graduated-sequential compression, the distal aircell inflates to $52 \mathrm{mmHg} \pm 5.2 \mathrm{~mm}$, followed 0.3 seconds later by inflation of the proximal aircell to $45 \mathrm{mmHg} \pm 4.5 \mathrm{~mm}$. After six seconds the aircells deflate. This cycle repeats every minute. The calf cuffs were applied to both lower limbs directly after the operation in the recovery room and the system was activated. The use of the IPC was continued until the tenth post-operative day whenever the patient was in bed. Checks of the correct functioning of the system and tight application of the cuffs were made several times each day. The patients and clinical staff (physicians, nursing staff and physiotherapists) were informed of the need for compliance with these criteria. When the IPC was discontinued the patients were fitted with graduated compression stockings on both legs.

Patients without thromboembolic complications while in hospital continued self-administration of LMWH until the 30th post-operative day and wore GCS for a maximum of three months.

Statistical analysis. The sample size and power calculation were based on 39 to 79 patients for each group with an expected incidence of thromboemboli of $11 \%$ to $25 \%$ in the LMWH/GCS group, and of $1 \%$ to $5 \%$ in the LMWH/
Table I. Baseline characteristics (mean, range) and peri-operative data of the 131 patients*

\begin{tabular}{|c|c|c|}
\hline & $\begin{array}{l}\text { LMWH/IPC } \\
\text { group }(n=68)\end{array}$ & $\begin{array}{l}\text { LMWH/GCS } \\
\text { group }(n=63)\end{array}$ \\
\hline Number of patients with THR & 33 & 28 \\
\hline Number of patients with TKR & 35 & 35 \\
\hline Gender (male:female) & $28: 40$ & 19:44 \\
\hline Mean age (yrs) & 63 (29 to 90$)$ & 65 (36 to 87 ) \\
\hline Mean weight (kg) & $78(50$ to 108$)$ & 77 (42 to 110$)$ \\
\hline Mean BMI (kg/m²) & 28 & 29 \\
\hline \multicolumn{3}{|l|}{ Number of patients with: } \\
\hline Previous cancer & 4 & 2 \\
\hline Previous thromboembolism & 5 & 3 \\
\hline Diabetes mellitus & 12 & 12 \\
\hline Hypertonia & 32 & 31 \\
\hline Heart disease & 12 & 13 \\
\hline Lung disease & 3 & 5 \\
\hline Varicose veins & 45 & 39 \\
\hline Smoking & 10 & 6 \\
\hline \multicolumn{3}{|l|}{ Premedication } \\
\hline Oestrogens & 4 & 2 \\
\hline Aspirin & 11 & 8 \\
\hline $\begin{array}{l}\text { Non-steroidal anti-inflammatory } \\
\text { agents }\end{array}$ & 25 & 26 \\
\hline \multicolumn{3}{|l|}{ Diagnosis } \\
\hline Osteoarthritis & 51 & 52 \\
\hline Chronic polyarthritis & 1 & 0 \\
\hline Dysplasia & 10 & 4 \\
\hline Other & 6 & 7 \\
\hline Prosthesis (right:left) & $42: 26$ & $31: 32$ \\
\hline Uncemented & 31 & 38 \\
\hline Hybrid & 8 & 6 \\
\hline Totally cemented & 29 & 29 \\
\hline \multicolumn{3}{|l|}{ Anaesthesia } \\
\hline General & 19 & 17 \\
\hline Regional & 49 & 46 \\
\hline \multicolumn{3}{|l|}{ Mean time (mins) } \\
\hline Anaesthesia & 133 (80 to 195$)$ & 137 (70 to 210$)$ \\
\hline Operation & 89 (55 to 177$)$ & 93 (46 to 159 ) \\
\hline Patients with retransfusion & 55 & 46 \\
\hline Mean amount (ml) & 351 (150 to 1150 ) & $342(150$ to 1150$)$ \\
\hline Mean drainage amount (ml) & 689 (210 to 2140$)$ & $624(100$ to 1930$)$ \\
\hline
\end{tabular}

* intergroup differences were not significant for all items

IPC group. Thus, an expected absolute thrombosis-difference of $10 \%$ to $20 \%$ between the two groups with a significance value of $5 \%$ and a power of $80 \%$ was assumed.

Patients were randomly stratified by the two types of operation (THR and TKR) and whether they had received general or regional anaesthetic, since a higher prevalence of thrombosis had to be assumed after TKR and general anaesthesia, respectively.

The $\mathrm{p}$ value for the effect of prophylaxis on the rate of thrombosis was determined in consideration of stratified randomisation with exact logistic regression (Program LogXact for Windows Version 2.1, CYTEL Software Corporation, Cambridge, Massachusetts).

\section{Results}

Of the 139 patients enrolled in the study, eight were subsequently excluded (two from the LMWH/IPC and six from the LMWH/GCS group) for various reasons such as non- 
Table II. Prevalence and site of the thromboses in the LMWH/GCS group

\begin{tabular}{llc}
\hline & \multicolumn{2}{c}{$\begin{array}{l}\text { Number of patients with } \\
\text { thrombosis (n = 18) }\end{array}$} \\
\cline { 2 - 3 } & After THR & After TKR \\
\hline $\begin{array}{l}\text { Prevalence of thrombosis in total (\%) } \\
\begin{array}{l}\text { Distal sites } \\
\quad \text { Fibular veins }\end{array}\end{array}$ & $4(14.3)$ & $14(40.0)$ \\
$\quad \begin{array}{l}\text { Fibular and posterior tibial veins } \\
\quad \text { Posterior tibial veins }\end{array}$ & 1 & 7 \\
$\begin{array}{l}\text { Proximal sites } \\
\quad \text { Popliteal veins (and fibular and posterior tibial veins) }\end{array}$ & 1 & 3 \\
\hline
\end{tabular}

compliance, confinement to bed for more than one week, premature transfer to a different institution or re-operation or discharge from hospital without ultrasonography. A total of 131 patients was assessed. The baseline characteristics of the patients and data on the operation and anaesthesia are given in Table I.

At the first follow-up between the sixth and 12th postoperative day no deep-vein thrombosis occurred in the LMWH/IPC group. However, thrombosis, always on the ipsilateral side, was identified in 18 of the 63 patients $(28.6 \%)$ in the LMWH/GCS group. This difference was significant $(\mathrm{p}<0.0001)$. The prevalence and site of the thromboses after THR and TKR are given in Table II.

At the second follow-up between the sixth and 12th postoperative weeks, 105 of the 113 patients (93\%) who had received prolonged prophylaxis with LMWH and GCS were available for review. One fresh thrombosis was demonstrated sonographically. The remaining eight patients were contacted by telephone and none had thromboembolic symptoms. There were no cases of symptomatic pulmonary embolism.

IPC was often used incorrectly at the beginning of the study. In most of the cases the cuffs had not been applied tightly enough or the system had not been activated. This situation was rectified. All except four patients had continuous IPC up until the end of the first post-operative day, and subsequently for up to at least six to eight hours daily. Thirty-four patients tolerated the compression for up to 12 to 16 hours daily. Eighteen patients $(27 \%)$ stopped using IPC prematurely, six between the second and fourth postoperative days and 12 between the fifth and ninth days. This was because their increasing mobility prevented much, if any, daytime use of the system. Its use at night was refused by these patients because it was uncomfortable. The noise of the IPC system while in operation had a negligible effect.

\section{Discussion}

No thromboembolic complications occurred after THR and TKR with the combined use of LMWH and IPC. Thrombosis occured relatively frequently with the LMWH/ GCS prophylaxis. The rates of thrombosis of $14 \%$ and $40 \%$ are comparable with those of randomised studies with enoxaparin in which thromboses were confirmed by venog- raphy in between $6 \%$ and $25 \%$ of patients after $\mathrm{THR}^{12,14-}$ 20 and in between $23 \%$ and $37 \%$ after TKR. ${ }^{21-24}$

Good compliance of patients and clinical staff is essential for the optimal efficacy of the compression system. ${ }^{25}$ The easier, more comfortable and less constrictive the IPC system is, the better is the compliance. Leg cuffs are not as well tolerated as cuffs on the calf or foot. ${ }^{26}$ In comparison with GCS, the IPC requires more supervision, and it is very important that patients and clinical staff are appropriately informed particularly at the start of treatment. Use of IPC should start immediately after surgery. Activation of the system before or during surgery seems to be self-defeating since a rate of thrombosis of $14 \%$ to $54 \%{ }^{6,8,11}$ is comparable with the $10 \%$ to $50 \% 7,9,10,12,13$ when starting after surgery. Exact indications of the length of time during which IPC is used are rare in the literature. Westrich and Sculco ${ }^{27}$ showed a significant inverse relationship between the total time that the IPC was used and the rate of thrombosis in patients undergoing TKR who had received aspirin in combination with IPC for prophylaxis. In patients in whom a thrombosis was demonstrated, the IPC had been used longer, on average for $96 \pm 23.4$ hours or daily for $19.2 \pm$ 5.1 hours as opposed to $67 \pm 21.1$ hours or daily for $13.4 \pm$ 4.3 hours. In our study we considered it essential that IPC was in continuous use until the end of the first post-operative day and subsequently for at least six to eight hours daily depending on the mobility of the patients. The stimulating effect of the IPC on the venous circulation in the early post-operative period when mobility is limited is particularly important and the longer it is used the better. However after the patients have been mobilised the calf muscle pump counteracts venous stasis and the IPC can be discontinued. However none of the patients who discontinued the IPC prematurely developed a thrombosis.

About a quarter of the patients (27\%) stopped using the IPC prematurely. This rate is comparable with the $25 \%$ described by Blanchard et al. ${ }^{6}$ The reasons for discontinuing in our trial were the relatively early mobility of the patients so that the IPC was hardly activated during the day. Night-time use was refused. Nonetheless, none of these patients had a thrombosis, so that the optimal period of use of the IPC may be related to the mobility of the patients.

We recommend the additional use of IPC to peri- and post-operative thromboembolic prophylaxis with LMWH 
in patients undergoing THR or TKR since LMWH and GCS provides insufficient prophylaxis.

The study was supported by an unrestricted grant from Aircast Europa GmbH, Neubeuren, Germany, which made the VenaFlow System during the study period.

No other benefits in any form have been received or will be received from a commercial party related directly or indirectly to the subject of this article.

\section{References}

1. Geerts WH, Heit JA, Clagett GP, et al. Prevention of venous thromboembolism. Chest 2001;119 (Suppl 1):132-75.

2. Partsch H, Blättler W. Guidelines for thromboembolic prophylaxis: revised version [article in German]. Phlebologie 2000;29:106-13.

3. Verstraete M, Prentice CRM, Samama M, et al. A European view on the North American fifth consensus on antithrombotic therapy. Chest 2000;117:1755-70.

4. Haas S. Prevention, diagnosis and therapy of thromboses in orthopedic and trauma surgery. Orthopäde 1997;26:1062-74.

5. Browse NL, Burnand KG, Irvine AT, et al. Diseases of the veins. Second ed. London, etc: Arnold, 1999.

6. Blanchard J, Meuwly JY, Leyvraz PF, et al. Prevention of deep-vein thrombosis after knee replacement: randomised comparison between a low-molecular-weight heparin (nadroparin) and mechanical prophylaxis with a foot-pump system. J Bone Joint Surg [Br] 1999;81-B:654-9.

7. Fordyce MJF, Ling RSM. A venous foot pump reduces thrombosis after total hip replacement. J Bone Joint Surg [Br] 1992;74-B:45-9.

8. Francis CW, Pellegrini VD, Marder VJ, et al. Comparison of warfarin and external pneumatic compression in prevention of venous thrombosis after total hip replacement. JAMA 1992;267:2911-15.

9. Haas SB, Insall JN, Scuderi GR, Windsor RE, Ghelman B. Pneumatic sequential-compression boots compared with aspirin prophylaxis of deep-vein thrombosis after total knee arthroplasty. J Bone Joint Surg [Am] 1990;72-A:27-31.

10. Hull RD, Raskob GE, Gent M, et al. Effectiveness of intermittent pneumatic leg compression for preventing deep vein thrombosis after total hip replacement. JAMA 1990:263:2313-17.

11. Kaempffe FA, Lifeso RM, Meinking C. Intermittent pneumatic compression versus coumadin: prevention of deep vein thrombosis in lower-extremity total joint arthroplasty. Clin Orthop 1991;269:89-97.

12. Warwick D, Harrison J, Glew D, et al. Comparisn of the use of a foot pump with the use of low-molecular-weight heparin for the prevention of deep-vein thrombosis after total hip replacement: a prospective, randomised trial. J Bone Joint Surg [Am] 1998;80-A:1158-66.

13. Wilson NV, Das SK, Kakkar VV, et al. Thrombo-embolic prophylaxis in total knee replacement: evaluation of the A-V Impulse system. J Bone Joint Surg [Br]1992;74-B:50-2.
14. Colwell CW Jr, Spiro TE, Trowbridge AA, et al. Use of enoxaparin, a low-molecular-weight heparin, and unfractionated heparin for the prevention of deep venous thrombosis after elective hip replacement: a clinical trial comparing efficacy and safety: Enoxaparin Clinical Trial Group. J Bone Joint Surg [Am] 1994;76-A:3-14.

15. Eriksson BI, Wille-Jørgensen $\mathbf{P}$, Kälebo $\mathbf{P}$, et al. A comparison of recombinant hirudin with a low-molecular-weight heparin to prevent thromboembolic complications after total hip replacement. N Engl J Med 1997;337:1329-35.

16. Lassen MR, Bauer KA, Eriksson BI, et al. Postoperative fondaparinux versus preoperative enoxaparin for prevention of venous thromboembolism in elective hipreplacement surgery: a randomised double-blind comparison. Lancet 2002;359: 1715-20.

17. Levine MN, Hirsh J, Gent M, et al. Prevention of deep vein thrombosis after elective hip surgery: a randomized trial comparing low molecular weight heparin with standard unfractionated heparin. Ann Intern Med 1991:114:545-51.

18. Planes A, Vochelle N, Mazas F, et al. Prevention of postoperative venous thrombosis: a randomized trial comparing unfractionated heaprin with low molecular weight heparin in patients undergoing total hip replacement. Thromb Haemost 1988; 60:407-10.

19. Spiro TE, Johnson GJ, Christie MJ, et al. Efficacy and safety of enoxaparin to prevent deep venous thrombosis after hip replacement surgery: enoxaparin clinical trial group. Ann Intern Med 1994;121:81-9.

20. Turpie AGG, Bauer KA, Eriksson BI, et al. Postoperative fondaparinux for prevention of venous thromboembolism after elective hip-replacement surgery: a randomised double-blind trial. Lancet 2002;359:1721-6

21. Bauer KA, Eriksson BI, Lassen MR, et al. Fondaparinux compared with enoxaparin for the prevention of venous thromboembolism after elective major knee surgery. N Eng/ J Med 2001;345:1305-10.

22. Colwell CW, Spiro TE, Trowbridge AA, et al. Efficacy and safety of enoxaparin versus unfractionated heparin for prevention of deep venous thrombosis after elective knee arthroplasty: Enoxaparin Clinical Trial Group. Clin Orthop 1995;321:19-27.

23. Faunø P, Suomalainen A0, Rehnberg V, et al. Prophylaxis for the prevention of venous thromboembolism after total knee arthroplasty: a comparison between unfractionated and low-molecular-weight heparin. J Bone Joint Surg [Am]1994;76-A: $814-8$

24. Leclerc JR, Geerts WH, Deskardins L, et al. Prevention of venous thromboembolism after knee arthroplasty: a randomized, double-blind trial comparing enoxaparin with warfarin. Ann Intern Med 1996;24:619-26.

25. Comerota AJ, Katz ML, White JV. Why does prophylaxis with external pneumatic compression for deep vein thrombosis fail? Am J Surg 1992;164:265-8.

26. Westrich GH, Specht LM, Sharrock NE, et al. Venous haemodynamics after total knee arthroplasty: evaluation of active dorsal to plantar flexion and several mechanical compression devices. J Bone Joint Surg [Br] 1998;80-B:1057-66.

27. Westrich GH, Sculco TP. Prophylaxis against deep venous thrombosis after total knee arthroplasty: pneumatic plantar compression and aspirin compared with aspirin alone. J Bone Joint Surg [Am]1996;78-A:826-34. 